This item was submitted to Loughborough's Research Repository by the author.

Items in Figshare are protected by copyright, with all rights reserved, unless otherwise indicated.

\title{
Reported growth following mountaineering expeditions: The role of personality and perceived stress
}

PLEASE CITE THE PUBLISHED VERSION

http://dx.doi.org/10.1177/0013916516670447

\section{PUBLISHER}

(c) The Authors. Published by SAGE Publications.

\section{VERSION}

AM (Accepted Manuscript)

\section{PUBLISHER STATEMENT}

This work is made available according to the conditions of the Creative Commons Attribution-NonCommercialNoDerivatives 4.0 International (CC BY-NC-ND 4.0) licence. Full details of this licence are available at: https://creativecommons.org/licenses/by-nc-nd/4.0/

\section{LICENCE}

CC BY-NC-ND 4.0

\section{REPOSITORY RECORD}

Smith, Nathan, Florence-Emilie Kinnafick, S.J. Cooley, and G.M. Sandal. 2019. "Reported Growth Following Mountaineering Expeditions: The Role of Personality and Perceived Stress". figshare. https://hdl.handle.net/2134/23470. 
1 Reported growth following mountaineering expeditions: The role of personality and

2 perceived stress

3

4

5

6

7

8

9

10

11

12

13

14

15

16

17

18

19

20

21

22

23

24

25 


\section{Abstract}

Results from previous studies suggest that stressful environmental conditions such as those faced on expedition may result in psychological growth. Building on previous research, the present cross-sectional study examined the role of personality and perceived stress in relation to post-expedition growth. Eighty-three participants who had completed a mountaineering expedition responded to measures of stress, personality, growth, well-being and resilience. Findings implicate perceived stress, and personality dimensions of agreeableness and openness, in post-expedition growth. Growth was associated with wellbeing but distinct from psychological resilience, highlighting the need to consider growth and resilience independently. Present findings support the proposition that stressful expeditionenvironments may promote positive psychological adjustment and identify factors that may influence this change. Research is needed to delineate the impact of other variables, such as coping, on changes that occurs during the post-expedition phase. Such research holds relevance for maintaining health following immersion in extreme and unusual environments. Keywords: Personality; Stress; Post-expedition Growth; Mountaineering; Expedition

\section{Introduction}

There are a number of inherent stressors associated with extreme environments, such as hostile climates, cramped living spaces, lack of available life support and limited communication with the outside world (Sandal, 2000). Despite these challenges, there is a growing body of literature that suggests exposure to stress as a result of operating in extreme environmental conditions can manifest in adaptive psychological responses and personal growth (Kjaergaard, Venables, Leon, \& Fink, 2013; Leon, Sandal, Fink, \& Ciofani, 2011). Such findings are consistent with the positive psychology orientation encouraged by Suedfeld (2001, 2005), and based on the presumed 'salutogenic' (or health-enhancing) function of challenging experiences (Antonovsky, 1987). Researchers conducting studies with diverse 
51 populations, such as young adult expedition-goers (Stott \& Hall, 2003), round-the-world 52 sailors (Kjaergaard, Leon \& Venables, 2015), polar adventurers (Atlis, Leon, Sandal \& 53 Infante, 2004; Leon et al., 2011), military personnel (Kjaergaard et a., 2013), Antarctic over54 winterers (Palinkas, 1986), and astronauts (Ihle, Ritsher \& Kanas, 2006; Suedfeld, Brcic, 55 Johnson, \& Gushin, 2012), have reported various forms of positive adjustment following 56 exposure to stress-inducing extreme environs. These findings contrast to the more traditional pathogenic view of extreme environments, which focused on psychological and interpersonal dysfunction experienced by personnel in such contexts (Steel, Suedfeld, Peri, \& Palinkas, 1997; Suedfeld, 2001).

In an attempt to explain the positive adjustment reported in previous studies, scientists focusing on psychological factors in extreme environment contexts have employed concepts embedded in the post-traumatic growth (PTG) literature (Calhoun \& Tedeschi, 2004). While extreme environments are not by nature considered traumatic, they do provide a challenging context that tests the personal resources of an individual and may result in enhanced feelings of personal strength, appreciation of life, and possibilities for the future. It is important to note that Calhoun and Tedeschi $(1996 ; 2004)$ consider growth as a process of positive adaptation that occurs following stressful and traumatic events, and emphasize a distinction from psychological resilience. In contrast to growth, resilience is more related to avoiding, warding off, and recovering from negative effects (Palinkas \& Suedfeld, 2008). Although the relationship between growth and resilience is debated (Lepore \& Revenson, 2006) and considered to be complex (Calhoun \& Tedeschi, 2006), initial evidence does support the

72 distinction between the two variables (e.g., Levine, Laufer, Stein, Hamama-Raz, \& Solomon, 73 2009). If resilience and growth are found to be independent constructs, this would highlight 74 the need to consider both variables when examining responses to stressful environments such 75 as expeditions. 
According to Calhoun and Tedeschi $(1996 ; 2004)$, there are several distinct changes that characterize PTG. These include, (a) improved perceptions of personal strength; (b) appreciation of life; (c) possibilities for the future; (d) relating to others; and (e) spiritual awareness. Personal strength relates to an enhanced belief in one's capabilities and having the resources needed to overcome challenging situations. Appreciation of life is associated with a positive view of the world and understanding what matters in life. Possibilities for the future refers to new opportunities that may not have presented themselves before encountering the stressful experience. Relating to others is about understanding and connecting with other people and spiritual awareness is being aware of and in touch with religious matters. Despite a number of studies examining growth following immersion in extreme conditions (e.g., Ihle et al., 2006; Kjaergaard et al., 2013), there has been little or no attempt to assess the correlates (i.e., personality, stress, well-being, resilience) of growth after returning from an extreme and unusual environment expedition.

Findings from previous work suggest that the extent to which a person is likely to report growth will be influenced by a variety of factors, which include the level of stress experienced and an individual's personality characteristics (Paton, 2005). Indeed, Shakespeare-Finch, Gow and Smith (2005) reported positive correlations between the Big-5 personality dimensions of extroversion, openness, agreeableness, and reports of PTG. Similar relationships between PTG and personality have also been found in other clinical (Garnefski, Kraaij, Schroevers, \& Somsen, 2008) and non-clinical (Tedeschi \& Calhoun, 1996) populations, thereby highlighting the importance of considering dimensions of personality when studying PTG.

Within extreme environment research, personality has often been a variable of interest and is an important consideration when screening people to operate in challenging conditions (Cardona \& Ritchie, 2007; Palinkas \& Suedfeld, 2008; Sandal, Leon \& Palinkas, 2006). For 
101 instance, the European and Russian Space Agencies and the National Aeronautics Space

102 Administration (NASA) screen applicants' personality prior to acceptance on to their

103 respective astronaut programs (Kanas \& Manzey, 2008; Musson, Sandal \& Helmreich, 2004).

104 The aim of this screening process is to remove candidates who are deemed unsuitable for 105 deployments in space.

106 In teams operating in challenging situations, a combination of high motivation

107 (instrumentality) and positive expressivity (interpersonal sensitivity) have been used to define

108 what is referred to as "the right stuff". The "right stuff" personality profile has been

109 associated with superior coping and performance in teams operating in stressful environments

110 such as aircrews (Chidester, Helmreich, Gregorich, \& Geis, 1991), military units (Sandal, et

111 al. 1998), submarine personnel (Sandal, Endresen, Vaernes \& Ursin, 1999), and astronauts

112 (McFadden, Helmreich, Rose, \& Fogg, 1994). Further evidence also exists to indicate that

113 agreeableness, the extent to which a person is affable and able to work with others, may

114 contribute to performance in demanding situations such as space missions and astronaut

115 training (Rose, Fogg, Helmreich, \& McFadden 1994). Instrumentality and agreeableness

116 (closely linked to positive expressivity) are very relevant to the present research, especially

117 given the importance of the study participants working with others to complete their

118 expedition objectives.

119 Personality profiling has also been popular with polar expedition groups and has been

120 used to assess a variety of individuals and teams operating in Arctic and Antarctic conditions

121 (Bishop, Grobler, Schjoll, 2001; Kjaergaard et al., 2013; Leon \& Scheib, 2007; Sandal,

122 Bergan, Warncke, Vaernes, \& Ursin, 1996). Findings from previous studies suggest that

123 individual characteristics such as high emotional stability, task ability, and social

124 compatibility predict optimal performance and adaptation during polar expeditions (Biersner

125 \& Hogan, 1984; Mocellin, Suedfeld, Bernaldez, \& Barbarito, 1991; Palinkas, Gunderson, 
126 Holland, Miller, \& Johnson, 2000). Further distinctions can be made between the types of

127 individual characteristics needed for optimum performance during different length

128 expeditions to the Polar Regions. The ideal personal characteristics for short-duration $(<3$

129 months) polar excursions are considered to be a high motivation to achieve, sense of

130 adventure, and low susceptibility to anxiety. In contrast, the individual characteristics ideal

131 for longer-duration stays and over-wintering are somewhat different and include amongst

132 others, being emotionally stable, introverted yet socially adept and not needing social

133 interaction (Palinkas \& Suedfeld, 2008). The participants in the present study were typically

134 undertaking short-duration expeditions and optimal performance would be expected to fit

135 within the former profile.

136 Taken together, findings from military, space, and polar expedition research point

137 towards certain personality factors, such as agreeableness, motivation, and low neuroticism

138 (or anxiety susceptibility) that are expected to facilitate performance and adjustment in

139 extreme environments (Musson et al., 2004; Sandal et al., 2006). However, to date there has

140 been a limited attempt to examine the link between personality and adjustment (i.e., growth)

141 specifically during the post-expedition phase. Given the role of personality factors in

142 predicting performance and adjustment (Palinkas et al., 2000), and considering research

143 conducted in trauma-related settings (e.g., Shakespeare-Finch et al., 2005), we might also

144 expect the same personality factors to contribute to reports of growth on return from extreme

145 and stressful environmental conditions.

146 In summary, the aim of the present study was to build on previous research examining

147 growth following an extreme environment expedition (e.g., Kjaergaard et al., 2013; 2015).

148 Specifically, in the current study we tested the relationship between PTG and correlates,

149 including stress, personality, well-being, and resilience. In line with previous findings, we

150 expected expedition-goers to report perceptions of growth. We expected growth to be 
151 positively related to well-being but not related to the distinct construct of resilience (Levine et

152 al., 2009). Finally, we anticipated that stress and personality would account for changes in

153 reported growth. It was expected that dimensions of personality consistent with the "right

154 stuff" (e.g., agreeableness, conscientiousness, openness) would be predictive of post-

155 expedition growth.

156

\section{Method}

\section{Participants}

In total, 83 mountaineering participants $($ Male $=72 ;$ Female $=11)$ were involved in

159 the present study. On completion of data collection, 93 expedition-goers had fully completed

160 the survey. After screening for expedition-type, 10 non-mountaineers were eventually

161 removed from the analysis resulting in the finally sample of 83 mountaineers. The final sample had a mean age of 42.54 years $(S D=16.50$ years $)$, had participated in at least 1 , and up to as many as 40 expeditions $(M=7.55)$, and on average had completed their most recent

164 expedition 28 months ago $(S D=48$ months). Of the participants, 31 were single, 42 were

165 married, 2 separated, and 8 co-habiting. In addition, 35 of the participants reported having

166 children. The study was approved by the University ethics committee prior to being

167 undertaken and all participants provided informed consent before taking part.

\section{Measures}

169 Post-expedition growth. To assess reports of post-expedition growth the 21-item

170 Post-traumatic Growth Inventory (PTGI; Tedeschi \& Calhoun, 1996) was used. The PTGI

171 assesses 5 dimensions of growth, including personal strength, appreciation of life,

172 possibilities for the future, relating to others, and spiritual matters. There were 4 items for

173 personal strength (e.g., "knowing I can handle difficulties"), 3 items were used to assess

174 appreciation of life (e.g., "an appreciation for the value of my own life"), 5 items used for

175 possibilities (e.g., "new opportunities are available which wouldn't have been otherwise”), 7 
176 items for relating to others (e.g., "a sense of closeness with others") and 2 items for spiritual

177 matters (e.g., "a better understanding of spiritual matters"). Participants were asked to

178 consider the extent to which they experienced change in relation to their last expedition.

179 Responses were provided on a 6-point scale, ranging from 0 (I did not experience this

180 change) to 5 (I experienced this change to a very great degree as a result of my expedition).

181 The PTGI has been used in previous expedition research and demonstrated acceptable

182 validity and reliability (Ihle et al., 2006; Kjaergaard et al., 2013). In previous work, alpha

183 coefficients for the PTGI subscales range from .77 to .97 (Ihle et al., 2006). Reliability

184 coefficients for the PTGI and other scales used in the present study are presented in Tables 1

185 and 3.

186 Subjective vitality. To examine participant well-being the Subjective Vitality Scale

187 (SVS; Ryan \& Frederick, 1997) was administered. The SVS contains 7 items tapping into the

188 extent to which a person feels alive and vital (e.g., I have energy and spirt). To answer each

189 of the questions, participants were provided with the stem "Since returning from my last

190 expedition, in general in everyday life..." and responded using a 7-point scale ranging from 1

191 (Not at all true) to 7 (Very true). The SVS has been used extensively in previous research

192 across a variety of domains and has been shown to be a valid and reliable indicator of well-

193 being (Bostic, Rubio \& Hood, 2000). Bostic et al. indicate typical alpha coefficients for the

194 SVS range between .80 and .89 .

195 Resilience. The Brief Resilience Scale (BRS; Smith et al., 2008) was used to assess

196 expedition-goers' reports of resilience. The BRS contains 6 items tapping into one dimension

197 of resilience (e.g., "I tend to bounce back quickly after hard times"). Participants were

198 provided with the stem "Since returning from my last expedition, in general in everyday

199 life..." and asked to respond to each item using a 5-point Likert scale from 1 (Strongly

200 disagree) to 5 (Strongly agree). The BRS provides an assessment of resilience as an outcome 
201 and offers information on the ability of a person to bounce-back consistent with the definition with the PTG literature (Windle, Bennett \& Noyes, 2011). Smith et al. (2008) reported acceptable levels of internal reliability for the BRS in four independent samples with

204 Cronbach alpha scores ranging from .80 - .91.

Stress. A single item was used to assess participants' perceptions of how stressful their expedition experience was. A scale based on the Borg (1982) system was used to capture perceptions of stress. Participants were given the stem "how stressful was the expedition listed above?" and asked to respond on a scale from 0 (least it could possibly be) 100 (most it could possibly be) in terms of how stressful they found the expedition experience. Single item measures of stress have shown good construct, content and predictive 211 validity in previous psychological studies (Elo, Leppanen \& Jahkola, 2003; Salminen, 212 Kouvonen, Koskinen, Joensuu, \& Vaananen, 2014) and have also been utilized in past extreme environment research (Kahn \& Leon, 2000). was used to assess the five personality traits of agreeableness, conscientiousness, 216 extraversion, openness and neuroticism. There were 9 items to assess agreeableness (e.g., "I am someone who likes to cooperate with others), 9 items to assess conscientiousness (e.g., "I am someone who does a thorough job"), 8 items for extraversion (e.g., "I am someone who has an assertive personality"), 10 items for openness (e.g., "I am someone who is original and 220 comes up with new ideas") and finally 8 items for neuroticism (e.g., "I am someone who is 221 depressed, blue"). Participants were given a series of statements and asked to consider the extent to which did or did not apply to them. A 5-point Likert scale ranging from 1 (Disagree strongly) to 5 (Agree strongly) was used to respond to each item. The BFI has demonstrated

224 reliability and validity in previous research and showed convergence (Soto \& John, 2009)

225 with the NEO personality inventory (Costa \& McRae, 1992) used in previous extreme 
226 environment research. In prior work, Soto and John (2009) have reported acceptable internal

227 reliability scores for the BFI with coefficients ranging between $.81-.88$.

\section{Procedure}

A cross-sectional retrospective design was employed in the study. Data were collected

230 using an online questionnaire that was completed in English and contained items related to

231 demographics, expedition characteristics and the variables under examination. Indices of

232 reliability for each of the study variables can be seen in Tables 1 and 2. Prospective

233 participants were contacted online via a number of mailing lists and pre-existing networks

234 within the mountaineering and expedition community. After reading the information letter

235 and criteria for inclusion, individuals were asked to provide consent. Following consent,

236 participants completed the different sections of the online questionnaire in relation to their

237 most recent expedition. In total, the questionnaire took approximately $20-30$ minutes to

238 complete.

239 Initially, the survey was promoted to all forms of expedition (e.g., mountaineering,

240 trekking, polar). However, on completion of data collection the convenience sample collected

241 were mainly mountaineers. Therefore, to be included in the study participants had to have

242 completed an alpine/mountaineering expedition lasting a minimum of 7 days. For the

243 purposes of this study an expedition was defined as a human powered journey between 2 or

244 more locations (i.e., from basecamp to a targeted[s] peak), which is consistent with how an

245 expedition is defined by the Royal Geographical Society in the UK.

\section{Data Analysis}

247 Aggregated scores for each of the questionnaire subscales were computed and

248 descriptive statistics presented alongside background information on the expeditions. To

249 examine the role of group size, expedition duration and expedition experience, variables were

250 dichotomized. For group size, participants were categorized into individual/small group $(N=$ 
$2511-4)$ and larger group $(N=5+)$. Expedition duration was considered shorter if the journey

252 lasted between $1-4$ weeks and longer if the trip was 5 weeks + . If the participants had

253 completed $1-4$ expeditions they were considered less experienced and those who had

254 completed 5+ trips were coded as more experienced. Coding the variables in such a way

255 resulted in roughly equal group sizes. Parametric assumptions were checked before

256 employing paired samples t-tests to examine differences in growth according to the coded

257 variables. As multiple t-tests were conducted, a Bonferroni adjustment was applied to the

258 probability (i.e., $.05 / 3=.017$ ) value thereby reducing the chance of rejecting the null

259 hypothesis in error. Bivariate correlations were then computed between study variables

260 before running a hierarchical multiple regression analysis. Based on the initial t-tests and

261 correlational analysis, we controlled for expeditions completed and elapsed time since

262 completion in the first step. In Step 2, stress was included as a predictor before adding

263 personality dimensions to the regression model in Step 3. At each stage, the amount of

264 variance was explained and the standardized regression weights assessed for significance.

\section{Results}

The location of the expeditions varied and included journeys in 38 different countries,

267 the most common being in Asia particularly in the Himalayas. There were a variety of other

268 locations visited by multiple expedition groups including the Andes, Patagonia, Namibia, the

269 European Alps, Alaska and Antarctica. Out of the 83 participants, 72 reported to have

270 achieved their expedition aims while 11 said they did not complete what they set out to do.

271 iii In terms of characteristics, there was a similar dispersion of participants between the more

272 than 1 week - less than $2(n=26)$, more than 2 weeks - less than $4(n=23)$, and more than 4

273 weeks - less than $8(n=27)$. There were fewer participants in the more than 8 weeks - less

274 than $12(n=4)$, and more than 12 weeks $(n=3)$ time frames. The size of the expedition

275 groups varied; 3 reported being individuals, 18 as part of a pair, 16 in a group of $3-4,29$ in a 
276 group of $5-8$ people and 17 who completed their trip as part of group of 9 people or more.

277 In relation to the expedition aims, participants reported wanting to complete first ascents,

278 explore remote environments and gain new experiences.

279 Reports of post-expedition growth are provided in Table 1. Scores indicate that

280 personal strength and appreciation of life displayed the most prominent perception of change,

281 while spiritual matters changed the least. With the exception of 1 item (i.e., "I have a stronger

282 religious faith"), $44-84 \%$ of individuals indicated some degree of change and reported

283 feelings of growth following the expedition. Independent samples $t$ tests were used to

284 examine growth according to expedition characteristics (see Table 2). A Bonferroni

285 adjustment was applied due to the repeated $t$ tests and a more conservative estimate of

286 significance was set at $p<.017$. There were no significant differences in reported growth

287 according to group size or duration of expedition. A difference was observed between

288 reported growth according to the level of expedition experience (i.e., more or less

289 experienced). Although this was non-significant according to the adjusted $\mathrm{p}$ value $(p=.033)$,

290 the effect size $(d=0.48)$ could be interpreted as moderate.

291 Mean scores, standard deviations and reliability values for the remaining study

292 variables can be seen in Table 3. Reported expedition stress was scored at a moderate level.

293 On average, participants reported higher scores on extraversion, conscientiousness,

294 agreeableness, and openness, and lower scores on neuroticism than when considered in

295 relation to a more general population (see Table 3).

296 Reports of growth, including future possibilities, appreciation of life, relating to

297 others, and spiritual matters were correlated with subjective vitality but not with resilience.

298 Reports of expedition stress were positively associated with dimensions of growth, including

299 appreciation of life, possibilities for future, personal strength, and relating to others. With

300 respect to personality, there was a significant association between extraversion and spiritual 
301

matters. A series of positive correlations were also found between agreeableness and future possibilities, appreciation of life, relating to others, and spiritual matters. Finally there was a significant positive correlation between openness, and appreciation of life and spirituality. A full correlation matrix with all study variables can be seen in Table 4.

Results from the hierarchical multiple linear regressions are presented in Table 5. Predictors included in Step 1 accounted for only 3\% of the variance in participants' reports of growth. Neither the number of expeditions completed or elapsed time was significantly related to growth. Including reports of expedition stress in Step 2 accounted for an additional $11 \%$ of the variance in participants' reports of growth and the regression was significant $F(3$, $79)=4.35, p=.007$. At this stage, stress emerged as a significant predictor of overall growth $(B=.35, p=.002)$. In Step 3, personality factors were added and this accounted for an additional $22 \%$ of the variance in growth and resulted in a significant regression coefficient $F$ $(8,74)=4.45, p<.01$. Stress remained a significant positive predictor of growth $(B=.39, p<$ $.01)$ and agreeableness also emerged as a significant positive predictor $(B=.34, p=.001)$.

The relationship between openness and growth was positive and approached significance ( $B$ $=.20, p=.07)$.

The aim of the present work was to examine the expedition characteristics and key psychological factors associated with post-expedition growth. To date, post-expedition responses have received relatively limited empirical attention. This is surprising given that the return stage has been identified as an important phase for indivduals following exposure to extreme environmental conditions. While a small number of studies have provided descriptive information on post-expedition growth, there has been no attempt to examine the correlates of growth following expeditions in extreme environment settings. In a unique contribution to the literature, the findings of the present research highlight the role of 
326 perceived stress and personality for ensuing reports of post-expedition growth. Dimensions of

327 growth were also associated with indicators of psychological wellbeing highlighting the

328 potential benefits of facilitating growth experiences.

329 Consistent with the findings of previous research, the expedition-goers in the present

330 study reported small-to-moderate growth following exposure to an extreme and unusual

331 environment (Ihle et al., 2006; Kjaergaard et al., 2013). Most notably, perceptions of personal

332 strength and appreciation of life were reported as having changed. The perceptions of growth

333 reported suggest that as a result of the expedition, participants felt more capable of

334 overcoming future challenges and had a different perspective of their life. The present

335 findings are in line with the literature on PTG (Tedeschi \& Calhoun, 1996), which suggests

336 stressful encounters may lead to a positive readjustment and hold benefits for the individual.

337 In addition, and consistent with previous findings (e.g., Ihle et al., 2006; Suedfeld \&

338 Weiszbeck, 2004), changes in spiritual matters were negligible. For such a shift to occur in

339 relation to spirituality, it is possible that a major event or more profound experience would be

340 needed, rather than the environmental stress caused by expedition endeavors.

341 To better understand the growth response, we examined key expedition characteristics

342 that might account for the positive adjustment (i.e., experience, duration, group size).

343 Although no significant differences emerged, the moderate effect size noted between the

344 more versus less experienced expedition-goers, suggests that the number of expeditions

345 completed could have an impact on growth. The finding related to expedition experience is

346 not surprising given that those who spend more time in stressful environments are likely to

347 become accustomed to such settings and perhaps develop resources to cope with these

348 situations. Consequently, the personal resources of experienced individuals are less likely to

349 be challenged and growth would be unexpected. In Step 3 of the regression model, the link

350 between expeditions completed and growth approached significance. In part, expedition 
351 experience may explain the modest changes in growth reported in the current work, as well as

352 in previous studies that focused on those operating in space (Ihle et al., 2006). This

353 interpretation is consistent with a plateauing effect, which suggests that substantial growth

354 will occur following initial expedition experiences and then become more stable over time.

355 Aligned with theoretical predictions, further growth would only then occur following more

356 demanding (or traumatic) expedition endeavors. Ultimately, events that challenge the

357 resources of an individual will result in a schema change, reformulation of one's self-

358 perception, and reports of growth. In future work, examining how growth is experienced by

359 both novice and more established expedition-goers could provide valuable information on

360 how extreme environments could be used to facilitate positive development. This information

361 could be used to aid the training and preparation of personnel for engagement in more

362 stressful extreme environment endeavors (Kanas et al., 2007).

363 Within the present sample, participants reported higher scores on conscientiousness,

364 agreeableness, extraversion, and openness, and lower scores on neuroticism than when

365 compared to a general population sample of adults (Noftle \& Robins, 2007). This personality

366 profile is coherent with previous research that has examined individuals operating in extreme

367 and unusual environments (Kjaergaard et al., 2013; Steel et al., 1997). Such a profile is linked

368 to the ideal characteristics needed for short-term polar expeditions as proposed by Palinkas

369 and Suedfeld (2008). Having a high sense of adventure, a desire to achieve, and low

370 susceptibility to anxiety are considered important for performance and adjustment in polar

371 environments and may hold true for other expedition contexts, such as mountaineering

372 (Palinkas \& Suedfeld, 2008). In addition, the reports of conscientiousness and agreeableness

373 are suggestive of a profile that is consistent with having the "right stuff", or being high in

374 instrumentality and expressivity, which has been shown to be important for teams operating

375 in challenging contexts such as aircrews (Chidester et al., 1991), astronauts (McFadden et al., 
376 1994), and military personnel (Sandal et al., 1998). In the present study, the sample of

377 alpinists and mountaineers were self-selecting and responsible for the selection of themselves

378 and other team members. Therefore, ensuring individual members possess the attributes (e.g.,

379 conscientiousness, agreeableness) that would allow them to function optimally in extreme

380 environments is critical for the safe and successful completion of different expedition

381 activities.

Not surprisingly, reports of expedition stress were positively correlated with

indicators of growth, including future possibilities, appreciation for life, and personal

strength. These findings are consonant with the literature on PTG that suggest when a

person's resources are challenged they may experience a positive reaction, especially if they are able to overcome the difficulties faced (Calhoun \& Tedeschi, 1996; 2006). Interestingly

and consistent with the view that growth and resilience should be considered as distinct

constructs (Levine et al., 2009; Palinkas \& Suedfeld, 2008), there were no significant

correlations between the dimensions of growth as measured by the PTGI and resilience. The

390 present results are in line with findings by Levine et al. (2009) and highlight the

391 independence of resilience and growth in this extreme environment context. One possible

392 explanation is that growth is more likely a positive reformulation, rather than simply a

393 tendency to withstand or bounce back from a stressful encounter. Consequently, this finding

394 is in line with the recommendations made by Suedfeld (2001) and highlights the need to

395 consider the complementary variables of growth and resilience in future extreme environment

396 research.

397 Further positive correlations were found between dimensions of growth and

398 subjective vitality, an indicator of well-being linked to optimal functioning within the

399 eudaimonic perspective (Waterman, 1993). Interestingly, there was no correlation between

400 stress and subjective vitality. This finding is encouraging and suggests that growth 
401 experienced as a result of stress may have subsequent implications for promoting psychological health (i.e., subjective vitality), but that stress in and of itself is not well-being promoting. It is important to highlight that these data are correlational and causal pathways cannot be assumed. Nevertheless, such findings provide impetus for future research in this area and data from prospective studies would allow for a stress-growth-well-being model to 406 be tested further.

After controlling for number of expeditions completed and time since completion

408 (elapsed time), stress remained a positive predictor of growth. This might suggest that

409 regardless of expedition experience or the elapsed time since completion, if the expedition

410 experience was stressful enough to challenge an individual's resources they would be more

411 likely to report growth (also consistent with our earlier interpretation). In addition to stress, a

412 positive association between the personality dimension of agreeableness and growth

413 emerged, suggesting that those who are more affable and able to work with others are likely

414 to report more positive adaption following exposure to extreme and stressful environments.

415 The link between openness and growth was approaching significance and might suggest that

416 those individuals who are interested in new experiences and opportunities are likely to report

417 more growth. Such findings are line with previous research on PTG in disaster and

418 emergency settings (Paton, 2006). In relation to previous extreme environment work, high

419 agreeableness and to some extent openness (similar to a sense of adventure) have been

420 identified as important for individual and team performance in challenging conditions

421 (Biersner \& Hogan, 1984; Mocellin, Suedfeld, Bernaldez \& Barbarito, 1991; Palinkas et al.,

422 2000; Palinkas \& Suedfeld, 2008; Sandal et al., 1999). The present findings suggest that the

423 characteristics of agreeableness, and to some degree openness, may be important for

424 adjustment, and more specifically reports of growth during the post-expedition phase. When

425 included within the same model, the remaining dimensions of personality were not associated 
426 with growth. This suggests that factors other than personality may account for the

427 unexplained variance in the growth response. In upcoming work researchers may consider

428 variables such as personal values, which relates to a person's motivation and may also impact

429 upon adjustment after exposure to stress (Sandal \& Bye, 2015; Sandal, Bye, \& van de Vijver,

430 2011). Understanding the motives of expedition-goers is important, especially given that such

431 a group choose to participate in these activities. Examining the quality of motivation (i.e.,

432 Intrinsic or Extrinsic; Deci \& Ryan, 2000) and/or individuals' goal orientation, or conception

433 of success (Dweck \& Leggett, 1988; Nicholls, 1989), may explain how individuals respond to

434 self-imposed stress and account for variability in growth. Motivation has been well-studied in

435 other self-initiated contexts, such as sport, and may help explain how individuals respond and

436 adjust following exposure to extreme environmental conditions.

\section{Limitations}

438 It is important to acknowledge the limitations of the present study. First and foremost,

439 the study utilized cross-sectional data that relied on a retrospective account of the most recent

440 expedition. As such, we were lacking pre-measurement reports of personality, resilience and

441 vitality, which would have allowed us to control for changes in these variables following

442 individuals' most recent expedition experience. However, despite the retrospective nature of

443 the research, the present findings are consistent with previous work on personality predictors

444 for adaptation in extreme environment and provide validity to our results. This approach also

445 overcomes some of the constraints of previous extreme environments research that relies on

446 small sample sizes. Secondly, there are a number of factors that were not considered within

447 the study. In previous work in extreme environments, the coping strategies used by

448 expedition-goers have been shown to be important for adaptation and performance in the face

449 of stress (Nicolas, Sandal, Weiss, \& Yusupova, 2013). It is also likely that coping strategies,

450 such as problem- and emotion-focused approaches, would hold relevance for reports of 
451 growth following stressful experiences (Paton, 2006) and should be considered in future

452 work. Linked to the coping response, it is possible there is a stress threshold after which no

453 further growth would be reported and maladaptive responses may emerge. Although beyond

454 the scope of the present study, more work needs to be done to examine the threshold of stress

455 likely to result in growth whilst minimizing potentially adverse effects. Collecting temporal

456 assessments of growth (as well as challenges faced) during the post-expedition phase may

457 elucidate the link between stress and adjustment after exposure to extreme environments.

458 Thirdly, in the current work we employed a single item indicator of perceived stress. This

459 approach has been used in previous studies (Elo et al., 2003) and aimed to provide a global

460 indicator of perceived stress to aid the recall of participants. However, we acknowledge there

461 are a variety of stressors likely to emerge before, during and after exposure to extreme

462 settings. In future work, a more detailed description of stress could be taken to examine

463 whether certain types of stressor (e.g., danger, monotony, psychosocial, weather etc.) account

464 for reports of growth. Fourthly, the present research adopted a largely positive psychological

465 viewpoint consistent with the recommendation of Suedfeld (2001). The expedition-goers may

466 have experienced challenges on return from their experience that were not captured in the

467 present study. In future, considering both the benefits and challenges faced by individuals

468 during the post-expedition phase would be beneficial.

\section{Conclusions}

470 To our knowledge, this is the first study to examine the relationship between

471 personality, stress and growth after completing an extreme environment expedition. The

472 findings of the work are encouraging and highlight the potential ensuing benefits associated

473 with engagement in pursuits in stressful environmental conditions. It is important to caution

474 that although stress and growth are related, more work needs to be done to examine this

475 relationship, particularly as excessive levels of stress are likely to be marked by both adaptive 
476 and maladaptive responses. We also re-emphasize the importance of the personality factors of 477 agreeableness and openness, not only for optimal performance in stressful environments, but 478 also for adjustment in the post-expedition phase. A particular strength of the present work 479 was the considerable sample size, which is often acknowledged as a constraint to studying 480 groups in extreme conditions (Palinkas et al., 2004). In the future, studying mountaineering 481 groups may allow extreme environment researchers to recruit larger samples and aid 482 understanding of optimal performance and psychological adjustment both during and 483 following exposure to extreme environments. Knowledge from such studies could then be applied to the selection, preparation and training of individuals that are due to operate in stressful environments (Kanas et al., 2007).

\section{References}

Antonovsky A. (1987). Unraveling the mystery of health: How people manage stress and stay well. San Francisco, CA: Jossey-Bass.

Atlis M. M., Leon G. R., Sandal G. M., Infante M. (2004). Decision processes and interactions during a two woman traverse of Antarctica. Environment and Behavior, 36, 402-423. doi: 10.1177/0013916503262217

Biersner, R. J., \& Hogan, R. (1984). Personality correlates of adjustment in isolated work groups. Journal of Research in Personality, 18, 491-496. doi:10.1016/0092$\underline{6566(84) 90007-2}$

Bishop, S. L., Grobler, L. C., \& Schjoll. O. (2001). Relationship of psychological and physiological parameters during an Arctic ski expedition. Acta Astronautica, 49, 261270. doi:10.1016/S0094-5765(01)00104-7 and Exercise, 14, 377-81 
500 Bostic, T. J., Rubio, D. M., \& Hood, M. (2000). A validation of the Subjective Vitality Scale 501 using structural equation modeling. Social Indicators Research, 52, 313-324. doi: 10.1023/A:1007136110218

503 Calhoun, L. G., \& Tedeschi, R. G. (Eds.) (2006). Handbook of posttraumatic growth: $504 \quad$ Research and practice. Mahwah, NJ: Erlbaum.

505 Cardona, R. A., \& Ritchie, E. C. (2007). U.S. military enlisted accession mental health 506 screening: History and current practice. Military Medicine, 172, 31-35.

507 Chidester, T. R., Helmreich, R. L., Gregorich, S. E., \& Geis, C. E. (1991). Pilot personality 508 and crew coordination: Implications for training and selection. The International 509 Journal of Aviation Psychology, 1, 25-44. doi:10.1207/s15327108ijap0101_3

510 Costa, P. T. Jr., \& McRae, R. R. (1992). Revised NEO Personality Inventory (NEO-PI-R) and 511 NEO Five-Factor Inventory (NEO-FFI) professional manual. Odessa, Florida: $512 \quad$ Psychological Assessment Resources, Inc.

513 Deci, E. L., \& Ryan, R. M. (2000). The "what" and "why" of goal pursuits: Human needs and 514 the self-determination of behavior. Psychological Inquiry, 11, 227-268. doi:

516 Dweck, C. S., \& Leggett, E. L. (1988). A social-cognitive approach to personality and 517 motivation. Psychological Review, 95, 256 - 273. doi:10.1037/0033-295X.95.2.256

518 Elo, A.L., Leppänen, A. and Jahkola, A. (2003) Validity of a Single-Item Measure of Stress Symptoms. Scandinavian Journal of Work, Environment, \& Health, 29, 444-451.

521 Garnefski, N., Kraaij, V., Schroevers, M.J., \& Somsen, G.A. (2008). Posttraumatic growth 522 after a myocardial infarction: A matter of personality, psychological health, or cognitive coping. Journal of Clinical Psychology in Medical Settings, 15, 270-277. doi: $10.1007 / \mathrm{s} 10880-008-9136-5$ 
525 Ihle, E. C., Ritsher (Boyd), J. B., Kanas, N. (2006). Positive psychological outcomes of spaceflight: An empirical study. Aviation, Space, and Environmental Medicine, 77, 93-101.

John, O. P., Donahue, E. M., \& Kentle, R. L. (1991). The Big Five Inventory--Versions $4 a$ and 54. Berkeley, CA: University of California, Berkeley, Institute of Personality and Social Research.

Kahn, P. M. and Leon, G. R. (2000). "Group Climate \& Individual Functioning in an Allwomen Antarctic Expedition Team." Journal of Human Performance in Extreme Environments, 5, 35-43. doi: 10.7771/2327-2937.1005

534 Kanas, N., Sandal, S., Boyd, J., Gushin, V., Manzey, D., North, R., et al. (2009). Psychology and culture during long-duration space missions. Acta Astronautica , 64, 659-677.

Kanas, N., \& Manzey, D. (2008). Space psychology and psychiatry. Netherlands: Springer.

Kjaergaard, A., Leon, G. R., \& Venables, N. C. (2015). The psychological process of reintegration following a nine month/260 day solo sailboat circumnavigation of the globe. Scandinavian Journal of Psychology, 56, 198-202. doi: 10.1111/sjop.12192.

540 Kjærgaard, A., Venables, N. C., Leon, G. R., \& Fink, B. A. (2013). Personality, personal values and growth in military special unit patrol teams operating in a polar environment. Military Psychology, 25, 13-22. doi: 10.1037/h0094753

543 Leon, G. R., Sandal, G. M., Fink, B. A., \& Ciofani, P. (2011). Positive experiences and personal growth in a two-man North Pole expedition team. Environment \& Behavior,

546 Leon, G. R., \& Scheib, A. (2007). Personality influences on a two-man Arctic expedition, impact on spouse, and the return home. Aviation, Space, and Environmental Medicine, $78,526-529$. 
549 Lepore, S. J., \& Revenson, T. A. (2006). Resilience and posttraumatic growth recovery, 550 resistance and reconfiguration. In L. G. Calhoun \& R. G. Tedeschi (Eds.), Handbook

553 Levine, S. Z., Laufer, A., Stein, E., Hamama-Raz, Y., \& Solomon, Z. (2009). Examining the relationship between resilience and posttraumatic growth. Journal of Traumatic Stress, 22, 282-286. doi: 10.1002/jts.20409

McFadden T. J., Helmreich, R. L., Rose R. M., Fogg L. F. (1994). Predicting astronaut of posttraumatic growth: Research and practice (pp. 264-290). Mahwah, NJ: Erlbaum. effectiveness: A multivariate approach. Aviation, Space, and Environmental Medicine, 65, 904-9.

Musson, D. M., Sandal, G. M., \& Helmreich, R. L. (2004). Personality characteristics and trait clusters in final stage astronaut selection. Aviation, Space, and Environmental Medicine, 75, 342-349.

Mocellin, J. S., Suedfeld, P., Bernaldez, J. P., \& Barbarito, M. E. (1991). Levels of anxiety in

Nicholls, J. G. (1989). The competitive ethos and democratic education. Cambridge, MA: polar environments. Journal of Environmental Psychology, 11, 265-275. doi:10.1016/S0272-4944(05)80187-2 Harvard University Press.

Nicolas, M., Sandal, G. M., Weiss, K., \& Yusupova, A. (2013). Mars-105 Study: Timecourses and relationships between coping, defense mechanisms, emotions and depression. Journal of Environmental Psychology, 35, 52-58. doi:10.1016/j.jenvp.2013.05.001

Noftle, E. E., \& Robins, R. W. (2007). Personality predictors of academic outcomes: Big five correlates of GPA and SAT scores. Journal of Personality and Social Psychology, 93, 116-130. doi: 10.1037/0022-3514.93.1.116 
574 Palinkas, L. A. (1986). Health and performance of Antarctic winter-over personnel: A follow575 up study. Aviation, Space, and Environmental Medicine, 57, 954-959.

576 Palinkas, L. A., Gunderson, E. K., Holland, A. W., Miller, C., \& Johnson, J. C. (2000).

577 Predictors of behavior and performance in extreme environments: the Antarctic space 578 analogue program. Aviation, Space, and Environmental Medicine, 71, 619-25.

579 Palinkas, L. A., Johnson, J. C., Boster, J. S., Rakusa-Suszczewski, S., Klopov, V. P., Quan 580 Fu, X., \& Sachdeva, U. (2004). Cross-cultural differences in psychosocial adaption to 581 isolated and confined environments. Aviation, Space, and Environmental Medicine,

583 Palinkas, L. A., \& Suedfeld, P. (2008). Psychological effects of polar expeditions. Lancet, 371, 153-163. doi:10.1016/S0140-6736(07)61056-3

585 Paton, D. (2005). Posttraumatic growth in protective services professional: Individual, 586 cognitive and organizational influences. Traumatology, 11, 335-346. doi: $10.1177 / 153476560501100411$

Paton, D. (2006). Posttraumatic growth in emergency professionals. In. L. Calhoun \& R. Tedeschi (Eds.), Handbook of posttraumatic growth: Research and practice. Mahwah, NJ: Lawrence Erlbaum.

Rose, R. M., Fogg, L. F., Helmreich R. L., McFadden T. J. (1994). Psychological predictors of astronaut effectiveness. Aviation, Space, and Environmental Medicine, 65, 910-5.

Ryan, R. M., \& Frederick, C. (1997). 'On energy, personality and health: Subjective vitality as a dynamic reflection of well-being'. Journal of Personality, 65, 529-565. doi: 10.1111/j.1467-6494.1997.tb00326.x 
598

599

600

601

602

603

604

605

606

607

608

609

610

611

612

613

614

615

616

617

618

619

620

621

622

prospective cohort study of 16,385 forest industry employees. BMC Public Health, 14, 543-550. doi: 10.1186/1471-2458-14-543

Sandal, G. M. (2000). Coping in Antarctica: is it possible to generalize across settings. Aviation, Space, and Environmental Medicine, 71, 37-43.

Sandal, G. M., Bergan, T., Warncke, M., Vaernes, R. J., \& Ursin, H. (1996). Psychological reactions during polar expeditions and isolation in hyperbaric chambers. Aviation, Space, and Environmental Medicine, 67, 227-234.

Sandal, G. M., Bye, H. H., \& van de Vijver, F. J. R. (2011). Personal values and crew compatibility: Results from a 105 days simulated space mission. Acta Astronautrica, 69, 141-149. doi:10.1016/j.actaastro.2011.02.007

Sandal, G. M., \& Bye, H. H. (2015). Value diversity and crew relationships during a simulated space flight to Mars. Acta Astronautica, 114, 164-173. doi:10.1016/j.actaastro.2015.05.004

Sandal G. M., Endresen, I. M., Vaernes, R., \& Ursin, H. (1999). Personality and coping strategies during submarine missions. Military Psychology, 11, 381-404. doi:10.1207/s 15327876mp1104_3

Sandal, G. M., Grønningsæter, H., Eriksen, H. E., Gravraakmo, A., Birkeland, K., \& Ursin, H. (1998). Personality and endocrine activation in military situations. Military Psychology, 10, 45-61. doi:10.1207/s15327876mp1001_4

Sandal, G. M., Leon, G., \& Palinkas, L. (2006). Human challenges in polar and space environments. Environmental Science and Biotechnology, 5, 281-296. doi:10.1007/s11157-006-9000-8

Shakespeare-Finch, J. E., Gow, K, M., \& Smith, S. G. (2005) Personality, coping and posttraumatic growth in emergency ambulance personnel. Traumatology, 11, 325334. doi: 10.1177/153476560501100410. 
623 Smith, B. W., Dalen, J., Wiggins, K., Tooley, E., Christopher, P., \& Bernard, J. (2008). The Brief Resilience Scale: Assessing the ability to bounce back. International Journal of Behavioral Medicine, 15, 194-200. doi: 10.1080/10705500802222972

626 Soto, C. J., \& John, O. P. (2009). Ten facet scales for the Big Five Inventory: Convergence with NEO PI-R facets, self-peer agreement, and discriminant validity. Journal of Research in Personality, 43, 84-90. doi:10.1016/j.jrp.2008.10.002

Steel, G. D., Suedfeld, P., Peri, A., \& Palinkas, L. A. (1997). People in high latitudes: The "big five" personality characteristics of the circumpolar sojurner. Environment and Behavior, 29, 324-347. doi: 10.1177/001391659702900302

Suedfeld, P. (2005). Invulnerability, coping, salutogenesis, integration: Four phases of space

641 Suedfeld, P., Brcic, J., Johnson, P. J., \& Gushin, V. (2012). Personal growth following longduration spaceflight. Acta Astronautica, 79, 118-123. $\underline{\text { doi:10.1016/j.actaastro.2012.04.039 }}$

Suedfeld, P., \& Weiszbeck, T. (2004). The impact of outer space on inner space. Aviation, 645 Space, and Environmental Medicine,75, C6-C9. 
646 Tedeschi R. G., Calhoun L. G. (1996). The Posttraumatic Growth Inventory: Measuring the

647 positive legacy of trauma. Journal of Traumatic Stress, 9, 455-471.

$648 \quad$ doi: $10.1002 /$ jts. 2490090305

649 Tedeschi, R. G., \& Calhoun, L. G. (2004). Posttraumatic growth: Conceptual foundations and 650 empirical evidence. Psychological Inquiry, 15, 1-18. doi:

$651 \quad 10.1207 / \mathrm{s} 15327965 p l i 1501 \_01$

652 Waterman, A. S. (1993). Two conceptions of happiness: Contrasts of personal expressiveness 653 (eudaimonia) and hedonic enjoyment. Journal of Personality and Social Psychology, 654 64, 678-691. doi: 10.1037/0022-3514.64.4.678

655 Windle, G., Bennett, K. and Noyes, J. (2011). A methodological review of resilience 656 measurement scales. BMC Health and Quality of Life Outcomes. 9, 8-26.

657 doi:10.1186/1477-7525-9-8 
Table 1

Reports of Post-expedition Growth byIitem

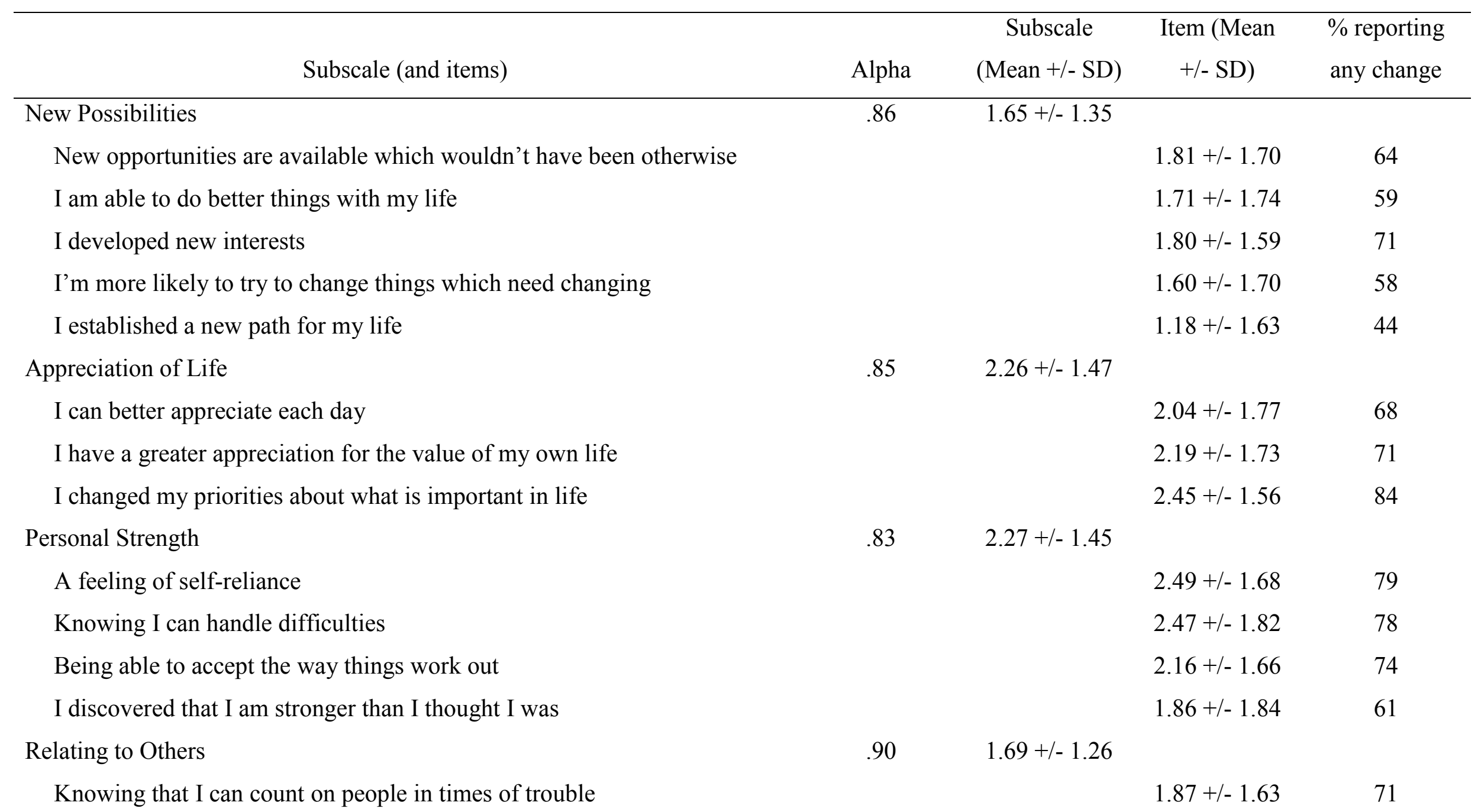


Having compassion for others

$1.62+/-1.57$

A sense of closeness with others

$1.96+/-1.67$

72

A willingness to express my emotions

$1.21+/-1.47$

Putting effort into my relationships

$1.82+/-1.64$

I learned a great deal about how wonderful people are

$1.66+/-1.76$

I accept needing others

$1.39+/-1.51$

Spiritual Matters

.61

$.75+/-1.07$

A better understanding of spiritual matters

$1.20+/-1.53$

I have a stronger religious faith

$0.28+/-0.87$

Note: Growth items range on scale from $0-5$ 
Table 2

Differences in Reported Growth Based on Expedition Characteristics

\begin{tabular}{lllll}
\hline \multicolumn{1}{c}{ Variables } & $\mathrm{N}$ & Mean (SD) & $t$ & Sig. \\
\hline Less Experienced & 38 & $2.01(1.13)$ & 2.17 & .033 \\
More Experienced & 45 & $1.48(1.07)$ & & .491 \\
\cline { 2 - 5 } Small group & 37 & $1.80(0.95)$ & 0.69 & .998 \\
Large group & 46 & $1.62(1.34)$ & & \\
Shorter duration & 49 & $1.72(1.08)$ & 0.01 & \\
Longer duration & 34 & $1.72(1.17)$ & & \\
\hline
\end{tabular}

Note: Less experienced $=1-4$ expeditions, More experienced $=5+$ expeditions; Small group $=1-4$ people, Large group $=5+$ people; Shorter duration $=1-4$ weeks, Longer duration $=5+$ weeks 
Table 3

Means, Standard Deviations and Reliability of Growth Correlates

\begin{tabular}{lcccc}
\hline & Mean & Std. Deviation & $\alpha$ & $\begin{array}{c}\text { General Population } \\
\text { Mean (SD) }\end{array}$ \\
\hline Stress & 46.83 & 23.14 & N/A & - \\
Time elapsed (months) & 28.30 & 48.21 & N/A & - \\
Expeditions completed & 7.55 & 7.68 & N/A & - \\
Extraversion & 3.50 & .85 & .88 & $3.26(.75)$ \\
Agreeableness & 3.89 & .58 & .75 & $3.71(.60)$ \\
Conscientiousness & 4.01 & .54 & .74 & $3.49(.62)$ \\
Neuroticism & 2.20 & .77 & .85 & $2.95(.72)$ \\
Openness & 3.89 & .43 & .57 & $3.55(.59)$ \\
Subjective Vitality & 4.84 & 1.11 & .87 & - \\
Resilience & 3.91 & .78 & .90 & - \\
\hline Note: Range for Stress & & & & - \\
\hline
\end{tabular}

Note: Range for Stress $=0-100$; Personality $=1-5$; Subjective vitality $=1-7$; Resilience

$=1-5$; Comparative general population sample of 10,497, $18-30$ year old students from Noftle \& Robins (2007) 
Table 4

Correlations Between Study Variables

\begin{tabular}{|c|c|c|c|c|c|c|c|c|c|c|c|c|c|}
\hline & 1 & 2 & 3 & 4 & 5 & 6 & 7 & 8 & 9 & 10 & 11 & 12 & 13 \\
\hline 1. Extraversion & 1 & & & & & & & & & & & & \\
\hline 2. Agreeableness & $.37 * *$ & 1 & & & & & & & & & & & \\
\hline 3. Conscientiousness & .11 & $.31 * *$ & 1 & & & & & & & & & & \\
\hline 4. Neuroticism & $-.40 * *$ & $-.42 * *$ & $-.22 *$ & 1 & & & & & & & & & \\
\hline 5. Openness & $.32 * *$ & .20 & $.27 *$ & -.09 & 1 & & & & & & & & \\
\hline 6. Stress & -.08 & -.14 & -.15 & .12 & -.11 & 1 & & & & & & & \\
\hline 7. Time elapsed & -.14 & -.17 & -.01 & .11 & -.03 & $.26^{*}$ & 1 & & & & & & \\
\hline 8. Possibility & .09 & $.25^{*}$ & .04 & -.02 & .16 & $.25^{*}$ & -.05 & 1 & & & & & \\
\hline 9. Appreciate Life & .13 & $.24 *$ & .02 & .07 & $.23 *$ & $.33 * *$ & -.03 & $.78 * *$ & 1 & & & & \\
\hline 10. Strength & .14 & .20 & -.04 & .07 & .03 & $.30 * *$ & -.01 & $.76^{* *}$ & $.76^{* *}$ & 1 & & & \\
\hline 11. Relating & .12 & $.32 * *$ & -.11 & .08 & .02 & $.24 * *$ & -.04 & $.72 * *$ & $.69^{* *}$ & $.69^{* *}$ & 1 & & \\
\hline 12. Spiritual & $.27 *$ & $.23 *$ & .01 & -.05 & $.31 * *$ & .19 & $-.23 *$ & $.56^{* *}$ & $.57 * *$ & $.45^{* *}$ & $.46^{* *}$ & 1 & \\
\hline 13. Subjective Vitality & $.33 * *$ & $.40 * *$ & .16 & $-.45 * *$ & $.32 * *$ & .01 & -.19 & $.42 * *$ & $.29 *$ & .19 & $.24 *$ & $.32 * *$ & 1 \\
\hline 14. Resilience & $.38 * *$ & $.26^{*}$ & .08 & $-.61 * *$ & $.35 * *$ & .07 & -.05 & .20 & .20 & .11 & .10 & .16 & $.59 * *$ \\
\hline
\end{tabular}

Note: $* p<.05 ; * * p<.01$ 
1 Table 5

2 Hierarchical Multiple Linear Regression Predicting Post-expedition Growth

\begin{tabular}{llcc}
\hline & & Beta & Sig. \\
\hline Step 1 & Elapsed time & -.08 & .459 \\
Step 2 & Expeditions completed & -.16 & .159 \\
\cline { 2 - 4 } Step 3 & Elapsed time & $.35^{* *}$ & .002 \\
& Expeditions completed & -.17 & .115 \\
& Stress & -.13 & .222 \\
& Elapsed time & $.39^{* *}$ & .000 \\
& Expeditions completed & -.11 & .273 \\
& Extraversion & $-.19+$ & .080 \\
& Agreeableness & .08 & .458 \\
& Conscientiousness & $.39 * *$ & .000 \\
& Neuroticism & -.12 & .299 \\
& Openness & .12 & .296 \\
& & $.20+$ & .070 \\
\hline
\end{tabular}

3 Note: Growth is computed as an aggregation of its 5 subscales; $* * p<.01,+p<.10$

4

\footnotetext{
i Separate hierarchical multiple linear regressions were conducted with each of the submissions of growth. The findings were consistent across dimensions with stress and agreeableness predictive the growth response. For parsimony, the results for overall growth are presented. Further information can be provided by the first author upon request.

ii On request from one of the reviewers, we examined the difference in stress and growth scores for completers (72) versus non completers (11). Those who completed the expedition reported perceived stress to be 43.72, whereas non-completers indicated perceived stress to be 59.09. Differences in growth scores between completers and non-completers were relatively small.
} 